\title{
The experience on a sport centre pilot plant with solar assisted heat pump and a look forward for new control strategies and technology upgrade
}

\author{
Luca Antonio Tagliafico ${ }^{1}$, Alessandro Cavalletti ${ }^{1}$, Chiara Marafioti $^{1}$, and Annalisa \\ Marchitto $^{1, *}$ \\ ${ }^{1}$ DIME/TEC, Scuola Politecnica, Università degli Studi di Genova, Via All’Opera Pia 15A, Genova, \\ Italia
}

\begin{abstract}
The pilot plant at the sport palace Palacus in Genoa is heated by a solar assisted heat pump, interfaced with a solar hybrid field and two integration gas burners. The heating system has been operating since 2012/13 and its performances have been collected almost continuously by means of a dedicated data acquisition system. The information and the experience acquired have been applied to the design of the revamping of the system, also considering the legislative changes occurred in Italy in the past decade, especially about photovoltaic production. The here presented case study allows the definition of some general design strategies to be implemented during the development of a new SAHP plant or when a revamping is required.
\end{abstract}

\section{The solar assisted heat pumps}

Solar Assisted Heat Pumps (SAHPs) belong to the family of technologies exploiting different renewable sources coupled together to obtain higher performances. The basic configuration interfaces the solar field with the cold side of the heat pump, increasing its efficiency. More in general, the coupling of ground or solar sources with the heat pumps allows a significative improvement in the global performance of the heating plants. Such complex systems are necessary because of the intermittent nature of the most widespread renewable sources (e.g., wind, solar, also known as Intermittent Renewable Energy Sources, IRES), to exploit the energy sources either in series or in parallel with others, according to their availability over time.

However, the critical point is represented by the replacement of fossil fuels with electricity. On one side, the heat pumps allow to reduce or even exclude the use of nonrenewable sources (e.g. natural gas, oil) while on the other side, the relevant electric consumption moves the problem to the electricity withdrawals from the national grid. Indeed, two main issues can be identified: the wide and deep penetration of heat pumpbased plants even in domestic applications might lead to frequent, critical overloads of the existing grid during specific periods of the year. In addition, the electricity provided by the

\footnotetext{
* Corresponding author: annalisa.marchitto@unige.it
} 
grid cannot be considered in principle as totally produced by means of renewable sources. These aspects led to advanced models of SAHPs interfaced with a photovoltaic field as well or a hybrid one to cover the electricity needs of the plant.

This upgrade is meant to create almost stand-alone installations with the aim of an almost stand-alone heating plant. Nevertheless, this goal can be hardly achieved without any supplementary device, since not always the peaks in solar PV production occur at the same time of the most relevant consumption, as in the case of a heating plant during winter.

Nowadays this problem represents one of the greatest obstacles to the diffusion of complex system exploiting the IRES such as the SAHPs with hybrid panels.

The problem is scarcely appreciated in existing civil installations, where the stand-alone configuration based on electric self-consumption is seldom achievable due to secondary factors, such as the compatibility with the surrounding environment. For instance, in case of solar panels, the available surface in civil buildings is often small and the capturing surface installed cannot cover the entire needs of the building/flat. On the other hand, the problem becomes more relevant as the plant increases its scale (and therefore consumptions) for instance in industrial applications or for heating systems of public buildings (for example sport palaces), as shown in [1] - [3]. As a consequence, the self-production and selfconsumption become the principal targets both to have economic benefits from the plant management and to mainly supply the electricity need by means of renewable sources.

On the other hand, the increasing PV diffusion over the territory, even at residential level [4], can represent a critical issue for the national grid since the dislocation in the electricity production can cause loss of balance between the produced and consumed energy [5].

The consequent response to these problems was found in the net metering, namely the possibility to use the electricity produced by the users anytime over a reference period, instead of only when it is generated. In other words, the national grid is used as a virtual storage instead of a real one, coupled to plants exploiting IRES which are non-dispatchable. This approach is nowadays still valuable although solar batteries experienced a significative diffusion along the past years, even though their convenience still lacks in absence of tax relieves (e.g. Ecobonus 110\%).

From a legislative point of view, the process, starting from the original Law 133/1999 up to the actual net metering approach, is very complex and it consists of different laws followed by regulatory resolutions enacted by the Manager of Energy Services. The most relevant variation was introduced by the Ministerial Decree 26/05/2015 (the so-called Minimum Requirements decree). In particular, annex 1, art.1, section iii states that any eventual surplus in the electrical production by means of renewable installations during given months cannot be considered to cover the consumptions in other different months.

On one side, the aim of the rule is to encourage and maximise the self-consumption, considering the surplus electricity only on a monthly basis, to avoid installations with the specific purpose of energy production and sale to the national grid. On the other side, this approach cannot fit the trend of an IRES such as the solar source. In addition to the daily variation, the solar source shows an intermittent variation along a year in which the peaks in the production are expected during the summer. This aspect means that before the Ministerial Decree 26/05/2015, the energy balance with the national grid could be made over a yearly basis, covering the peak consumption during winter with the summer production. In fact, in winter the PV panels cannot entirely cover the needs of the plant and an additional withdraw from the national grid occurs. The loss of this possibility caps the potential benefits deriving from the solar source since up to now no storages allow the use of the summer production (or other periods in which the PV production is high) to cover other periods during the year in which the consumption exceeds the self-consumption. 
Moreover, a PV field designed with the old criterion would result oversized so far and a significative amount of electricity produced would be lost.

In addition, the so-called PV batteries can be considered effective over a daily balance, to cover the needs during night with the daily produced electricity.

So, two limit cases can be considered:

1) The plant is sized to cover the electrical need in the month of maximum need. This implies a significative over-dimensioning with extremely high initial costs and a surplus of unexploited energy.

2)The plant is sized to cover the electrical need in the month of minimum need. This strategy allows the consumption of the entire amount of electricity produced and it results in low installation costs. The electrical need of the facility surely requires an integration from the national grid and the contribution of the solar source in the annual energy balance is minimal since the installation cannot fully take advantage of the irradiance available in summer.

Any other solution is included between these two extremes and the distance between them depends on the monthly variation of electricity need of the facility. Nevertheless, the full potential of photovoltaic applications is irremediably compromised due to the imposed monthly balance, since the ordinary variation of irradiance during a standard year cannot be exploited in profitable way.

Last but not least, the national policies also influence people's opinion and agreement towards the plant. Indeed, the same installation can result profitable or not according to the net metering criteria adopted (the old or the new one). In addition, the complexity of the plant scheme requires a higher level of automatization to exclude the end users' intervention as far as possible. In fact, the users might not have the technical skills to manage the warnings and blocks of the HP and they should not be asked to control step by step the heating plant. This issue briefly resumed is commonly associated to the term "acceptance" and it has to be correctly accounted even from the design stage [6] - [8]. Indeed, it plays a key role to determine whether a facility is used and therefore it can reach its expected performances. In the case of SAHPs, a frequent, low level of acceptance has been appreciated in the different pilot plants with a consequent loss of interest and use of this technology.

\section{Solar assisted pilot plant with hybrid panels at Palacus, University of Genoa: description, methodology and objectives for the case study}

The pilot plant at the Palacus Sport Palace of University of Genoa consists of a traditional gas-burners heating system, coupled to a solar assisted heat pump, interfaced with solar hybrid (PV-T) panels. Figure 1 provides an overview on the plant location.

The design of the pilot plant was carried out using commercial components. Indeed, the facility is an attempt to step forward into the level of technological readiness closer to the industrial marketing.

Its importance lies also in the size of the heated building: a sport palace of about $30.000 \mathrm{~m}^{3}$ provided with different gyms, lockers and sport fields.

The size of the plant represents another interesting feature: the solar hybrid field consists of $120 \mathrm{~m}^{2}$ of net capturing surface (about $50 \mathrm{~kW}_{\mathrm{T}}-20 \mathrm{~kW}_{\mathrm{E}}$ of peak power production). Its photovoltaic efficiency benefits of the thermal field which contributes to keep low working temperatures at the panels. 
Moreover, the plant works as a heating system and the operating range of the solar filed coupled to the heat pump is close to the air temperature, with negligible thermal losses, even with poorly insulated connection pipes.

The heat pump can give up to $62 \mathrm{~kW}_{\mathrm{T}}$ heating service associated to a peak electrical power consumption of $12 \mathrm{~kW}_{\mathrm{E}}$. The interface with the solar field increases its COP up to a maximum value of 5-5.5.

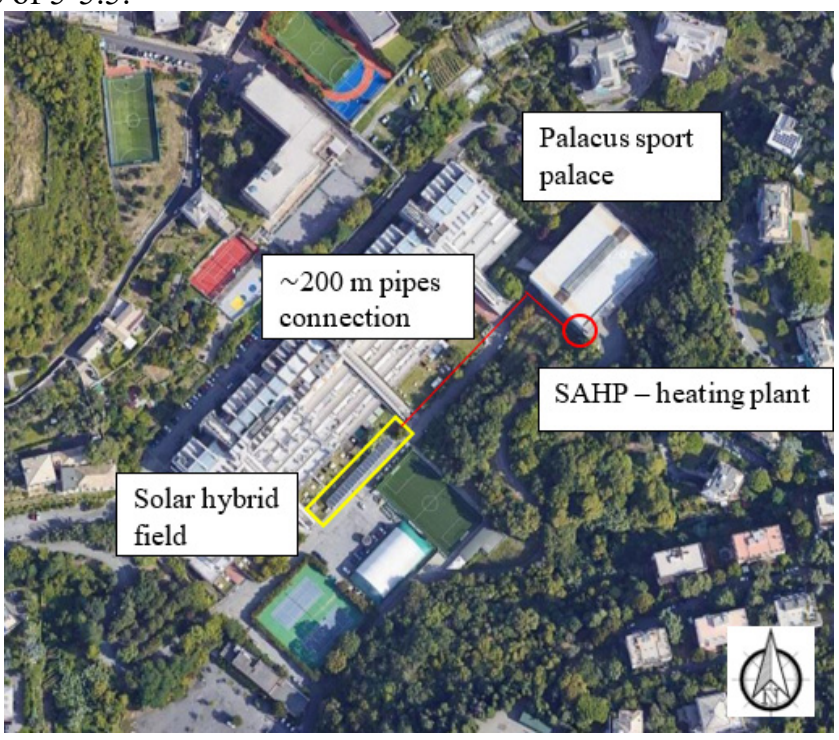

Fig. 1: layout of the Solar Assisted Heat Pump (SAHP) at the Palacus Sport Palace, Genoa

In the end, the Data Acquisition and control System (DAS) is the real core of the plant: an internet connected PLC allows the data collection and plant management in real time even remotely by means of about 50 measurement points and 15 control points. As regards to the methodology, a significative amount of data about the operation of the system can be either directly measured or computed. In addition, the information collected has been postprocessed to exclude any measurement associated to non-standard working of the plant, for instance due to maintenance or failure of DAS components/specific elements of the plant.

Indeed, the aim of the paper is to take the experimental results derived from the pilot plant, which already account for the end users' real needs and for the effective environmental conditions and put them into the wider context of a feasibility study. The target is to identify the most effective approach in the design/revamping of the plant, to achieve its best economic and technological performance. Such parameter depends also on the laws which regulate the use of renewable sources (e.g. the solar one). Furthermore, the validity of the approach can be extended to other plants, even in case of incomplete or lacking DAS. In fact, the illustrated concepts can be applied also basing on the more general information available in other documents such as the energy bill.

Nevertheless, an extended and working DAS does make the difference between a successful and unsuccessful plant, with the chance of a deeper insight on the plant working and performance.

The plant design dates back to the 2013 (before the Minimum requirements decree) and the key concept of the project is based on the use of the summer production to cover the electric needs of the HP during the heating season. According to this principle, the installed capturing surface would cover the HP electric consumptions with a surplus of about $40 \%$ delivered to the grid. 
According to the current net metering criterion (monthly energy balance instead of a yearly one) the same installation would loses its convenience since only about $40 \%$ of the total need of the HP is covered by the solar hybrid field, as shown in [3]. This dramatic change depends on the electricity produced and lost during summer since the heating plant is inactive.

The plant is under revamping to retrofit the solar field, to upgrade other components (e.g. gas burners, some pumps) and to extend the data acquisition system enlarging the number of sensors. Such intervention poses the problem of how the plant should interact with the national grid (especially the solar hybrid subsystem). The interest in this issue has a general validity since it could be applied to any solar field either existing or under design.

\section{Results of a yearly performance of the pilot plant}

This paragraph summarizes the experimental values of the specific plant performance according to the information collected almost continuously thanks to the DAS. The data refer to the year 2019, since 2020 shows non-standard trends, due to the lockdown periods.

A first meaningful analysis can be performed considering the trend of electrical consumption of the HP versus the photovoltaic production as shown in Figure 2.

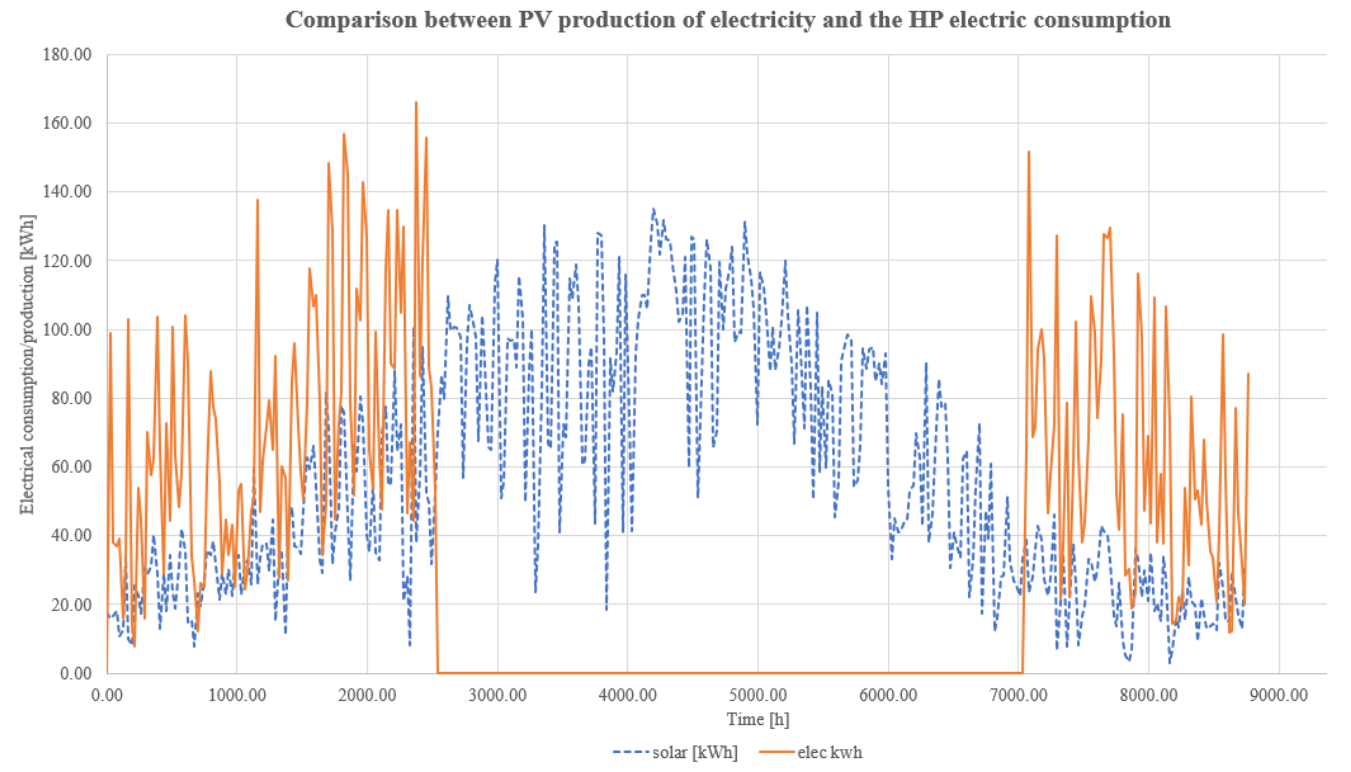

Fig. 2: plot of the electricity consumed by the heat pump (orange) and the photovoltaic production of the solar field (dotted blue).

The Figure 2 and the related table 1 report the trends of the PV production and the HP consumption

The electrical consumption of the heat pump drops to zero during summer, part of spring and autumn since the heating system is off. The production of the domestic hot water is covered by the gas burners directly interfaced with the solar field by means of a bypass. 


\begin{tabular}{|c|c|c|c|}
\hline Month & $\begin{array}{c}\text { Solar PV } \\
\text { production }[\mathrm{kWh}]\end{array}$ & $\begin{array}{l}\text { Heat Pump electric } \\
\text { consumption }[\mathrm{kWh}]\end{array}$ & $\begin{array}{r}\text { Monthly } \\
\text { balance }\end{array}$ \\
\hline January & 695 & 1913 & -1218 \\
\hline February & 879 & 1917 & -1038 \\
\hline March & 1634 & 3390 & -1757 \\
\hline April & 2142 & 1751 & 391 \\
\hline May & 2683 & 0 & 2682 \\
\hline June & 2910 & 0 & 2909 \\
\hline July & 3230 & 0 & 3229 \\
\hline August & 2591 & 0 & 2591 \\
\hline September & 1868 & 0 & 1868 \\
\hline October & 1116 & 1136 & -20 \\
\hline November & 703 & 2437 & -1734 \\
\hline December & 597 & 1796 & -1199 \\
\hline Total & 21047 & 14340 & -6575 \\
\hline
\end{tabular}

Table 1. Year 2019, HP consumption and hybrid solar field production. Comparison between old and new net metering criteria (positive values imply surplus of energy production while negative ones represent an additional withdraw from the national grid).

Coherently with the trend of solar irradiation during a year, the peak production is reached during summer. The electricity produced mainly winter and more in general during the heating season cannot cover the entire HP need in these months. A temporal gap of about six months between peak productions and consumptions can be noticed. If the storages/batteries were capable to provide such "inertia" to the system (like in the case represented by the national grid in the old net metering) the cost-benefit balance would result strongly positive. On the other hand, if the balance is carried out month by month, the summer production cannot be accounted due to the low/absent consumption of the plant. On the other side, the daily produced electricity during the winter is completely consumed and an additional withdraw from the national grid is required. Table 1 provides a month by month comparison between production and consumption. According to the old net metering criterion (before 2015) the electricity produced by means of the solar field is $21,047 \mathrm{kWh}$ while the HP consumption is about $14,340 \mathrm{kWh}$, with a surplus production of $6,707 \mathrm{kWh}$. 
The same system with the same performance when applying the net metering after 2015 would not result economically convenient. Indeed, the national grid should provide 6,575 $\mathrm{kWh}$, in addition to the energy produced by the solar field (and partly lost during summer). The yearly PV production of the solar field and the yearly HP consumption in Table 1 show good agreement with the expected performances [3]. Nevertheless, about $15 \%$ of the expected PV electricity is lost, due to the aging of the panels and the rupture of some of them.

At first sight, the trend of the HP consumption might not be as expected: the months which are likely to be the coldest during the heating season (e.g., January, December) show a lower consumption of the HP instead of others, such as March or the first weeks of April. This unexpected condition is basically related to the frequent failures experienced by the SAHP plant and the consequent users' low confidence in it (the typical "acceptance issue" to be faced by the new technologies). The failure of the heating system due to the block of the heat pump or the rupture of a panel implies two main negative consequences: firstly, the SAHP remains inactive up to the technical staff's intervention. Secondly, the complexity of the plant is a weakness of the facility and it can lead to frequent stoppages which require a specialised maintenance. Therefore, both the users and the technical staff feel often decide to bypass the SAHP in case of block instead of rebooting it. For example, after the rupture of a panel, the system needs a manual restart, but the staff often prefers to bypass the SAHP and use only the gas burners. In conclusion the lower, unexpected consumption in the coldest months are due to the switch from the SAHP to the traditional gas burners, due to an issue of users' acceptance [9], [10]. This topic is not specifically dealt in the present work, but it influences strongly the plant performance as shown by the measurements collected.

\section{New configurations to exploit the existing plant}

This section is meant to study how the plant could be improved and upgraded, basing on the operative information collected. The observations are clearly related to the specific case of the pilot plant under analysis, but the conclusions can be extended to other plants with similar characteristics. The need for these reflections is made compulsory by the constant evolution of the net metering and the possible use of solar batteries in the context of the revamping.

The change of the key concept of the plant design represents the first, crucial operation. Actually, the summer PV production is almost unexploited, so two possible design strategies are possible:

- Reduce the size of the PV plant: as illustrated in the previous chapters, the heat pump has a nominal peak consumption of electrical power of about $12 \mathrm{~kW}_{\mathrm{E}}$ while the current power installed in the solar field is of $20 \mathrm{~kW}_{\mathrm{E}}$ (almost twice the maximum power needed). The benefit would have many positive aspects: reduction in the energy lost during summer, reduction of maintenance and costs, since an inverter each $10 \mathrm{~kW}_{\mathrm{E}}$ is required. However, this strategy would lead to a significative loss in the plant potential, especially on the PV side and a more intensive use of the national grid.

- Increase the consumption of the plant: the original design of the plant has conceived the heating system and the correspondent solar field as part of a specific plant, made only to work in series, to exploit the old net metering. The goal is to employ the electricity produced (which should have covered the HP consumption over the year) for other needs which occur during summer. For instance, an air treatment unit for the sport palace is under design and its period of working is very likely to match the periods of maximum irradiance available (summer). 
The correct choice in the sizing of the solar field has to be carried out considering the energy needs of the sport palace as a whole. In particular, the peak consumed electric power shows an almost yearly cyclic oscillation, as shown in Figure 3. During summer, the peak power is about $20 \mathrm{~kW}_{\mathrm{E}}$ while during the heating season, this maximum value can be almost doubled $(35-40 \mathrm{~kW}$ ). This means that the SAHP can cover up to about the $30 \%$ of the peak consumed power. The other energy-intensive service is represented by the illumination of the sport fields (both internal and external). Indeed, the energy bill includes different prices for different time slots and therefore a first estimation of the periods with higher consumption can be carried out in terms of energy (Figure 4).

During the first period of the year, most of the energy consumed occurs during time slot F1 (from 8.00 a.m. up to 7 p.m. of each working day) which is overpassed by the consumption during time slot F3 (on Sundays and holydays and from 11.00 p.m. up to 7.00 a.m. of the following day for all the other days) only when spring/summer occurs (correspondent to an extended use of the sport field even during night). In the end, time slot F2 (from 7.00 a.m. up to 11.00 p.m. on Saturdays and from 7.00 a.m. to 8.00 a.m. and from 7.00 p.m. up to 23.00 p.m. during each working day) shows very little variation over the year and it can be considered on average between $25 \%$ and $30 \%$ of the total energy consumption.

The two parameters represented (peak power and energy required) allow to size the plant, trying to best fit the production with the energy request. In particular, the peak power installed $\left(20 \mathrm{~kW}_{\mathrm{E}}\right)$ can be considered acceptable, given that the solar field covers other needs of the structure during summer, while the winter consumption of the heat pump shall be mostly covered by means of the national grid.

The implementation of batteries cannot avoid this need, since the time gap between the periods of maximum consumption and maximum production is too large (order of magnitude of semesters). In addition, the storages work on a daily time scale and their presence would allow to use just between the $30 \%$ and the $50 \%$ of the total request. In fact, this percentage is consumed during the periods named F2 and F3 when the irradiation is low or absent. This parameter will define the capacity of the battery to avoid a poor or excessive storage.

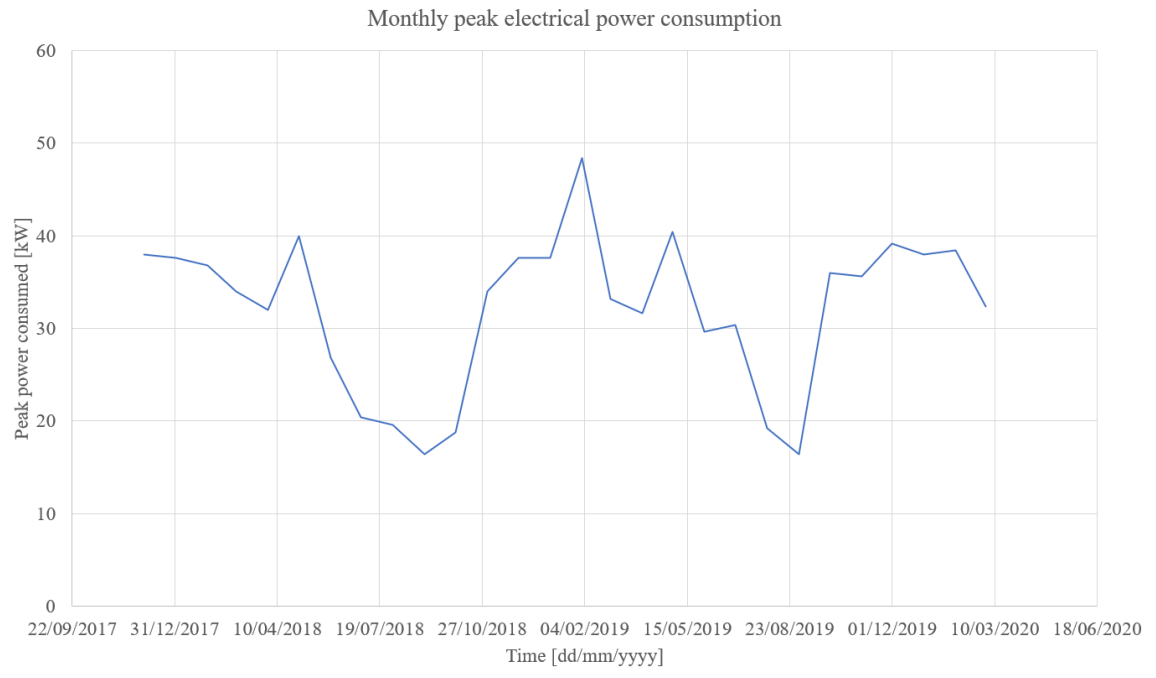

Fig. 3: plot of the peak consumed electric power by the sport palace over different years 


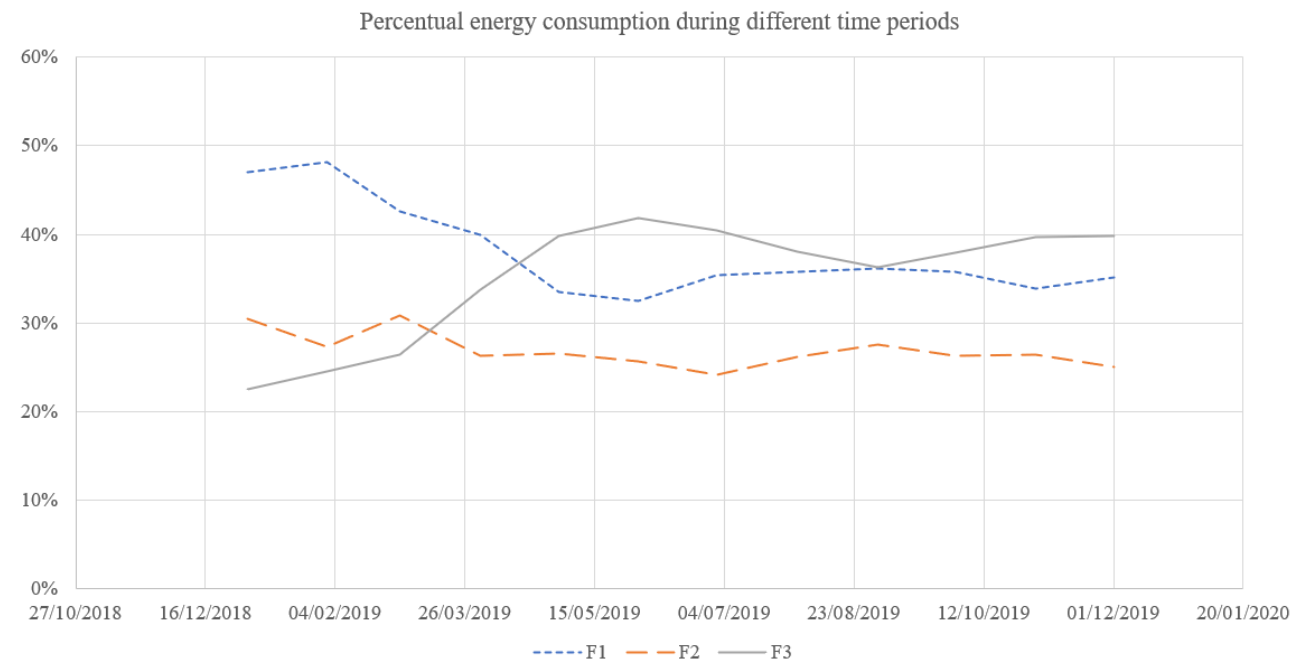

Fig. 4: percentual electric energy consumption during the different time slots. F1: from 8.00 a.m. up to 7 p.m. of each working day (blue dotted line). F2: from 7.00 a.m. up to 11.00 p.m. on Saturdays and from 7.00 a.m. to $8.00 \mathrm{a}$.m. and from $7.00 \mathrm{p} . \mathrm{m}$. up to $23.00 \mathrm{p} . \mathrm{m}$. during each working day (orange dashed line). F3: on Sundays and holydays and from 11.00 p.m. up to 7.00 a.m. of the following day for all the other days (grey continuous line).

In conclusion, Figure 3 alone can mislead the conclusions, since it represents an envelope of the maximum power, without any information on the duration of the withdraw at that specific power. The conjoint comparison of Figures 3 and 4 shows that the maximum relative consumption is associated to periods F2 and F3 (during the use of the outdoor field during evening or night) and therefore they are likely to have short durations. The minimum required power is about $20 \mathrm{~kW}_{\mathrm{E}}$ and it occurs during summer. So as a first approximation the case of increasing the consumption of the plant connected to the PV field could avoid the resizing of the actually installed hybrid field. On the other hand, an increase in the installed peak power would result in complications for the management of the solar field (e.g. stricter security checks and protocols) and it would hardly meet the brief and high peaks of consumption mainly due to the illumination of the sport palace (outdoor and indoor).

\section{Conclusions and future developments}

The solar assisted heat pumps represent a high potential technology where the renewable sources are coupled to a heat pump to reach very efficient results. In particular, the use of heat pumps shifts the consumption from fossil fuels (e.g. natural gas) to electricity and therefore the coupling with either a PV or a hybrid solar field represents one of the most relevant chances to reach a stand-alone installations with on-site consumption. This goal would avoid or at least reduce potentially critical situations on the national grid which has not been designed to cover the massive use of heat pumps. However, modifications of the laws concerning the net-metering occurred and they made the target of almost total self-consumption unattainable. In fact, the peak in the winter consumption of a heat pump system can no longer be covered with the summer production of the PV/hybrid field. Consequently, the diffusion of these plants over the territory experienced a significant slow-down in the past decades. Moreover, no common approach in the design of solar assisted heat pumps exists and therefore the sizing and the design are left to the knowledge 
and sensibility of the technical staff. This work presents the case study of the solar assisted heat pump interfaced with hybrid panels at the sport palace Palacus - University of Genoa where the revamping has brought the issue of how a proper design of the solar field could be carried out in the most profitable way. This topic refers to both new installations and existing ones which need a deep revamping.

Although few SAHP pilot plants were built, their design was performed according to the laws in force at that time. The fast evolution of policies about net metering in the past years has brought to attention the issue of revamping of such plants also according to these changes. Indeed, the replacement of damaged or aged elements with more efficient ones might not be sufficient and a radical change in the design concepts might be necessary. In the present work the revamping of the solar assisted heat pump at Palacus has been analysed to identify the interventions needed to restore the plant efficiency, with specific attention to the issue of the on-site photovoltaic production. The actual performances and the thermal needs of the sport palace were collected by means of the data acquisition and control system, but similar analyses can be carried out on other plants, even without the presence of an extended data acquisition and control system, since the minimum information required can be found on the energy bill as well. The hybrid solar field of the pilot plant results now oversized especially on the PV side, since the summer production no longer covers the winter consumption of the HP. As a consequence, either the solar field can be reduced or other electric needs can be integrated in the plant. In both cases, the target of self-consumption has to be considered lost. The best approach consists in including other existing energy intensive devices in the facility, such as lighting, to maximise the consumption of the produced electricity, above all in summer, when the heating system in not active. The use of batteries could extend the self-consumption even at night, but their size and their benefit have to be formerly compared to the distribution of the electrical needs of the facility. In the case study, their integration could allow the recovery up to about $30-50 \%$ of the total consumption, in particular during the summer. Such scenario needs a further simulation on the economic side to test its convenience and to estimate its payback period.

\section{Aknowledgement}

The pilot plant was built with an $80 \%$ co-funding of FSE Regione Liguria, Bando Azione 2.1 "Efficienza Energetica e Produzione di Energia da Fonti Rinnovabili - Enti Pubblici" - Posizione n.2. The present work was developed under the PRIN 2015 MIUR grant 2015M8S2PA "Clean Heating and Cooling Technologies for energy efficient smart grid". The monitoring and control system has been completed with the co-funding of University of Genoa, in the framework of the Project "Grandi Attrezzature" 2018, DR n. 3404, 19/07/2018).

\section{References}

1. G. Corallo, A. Franchi, A. Simonetti (ENEA), L. Di Rienzo, A. Fanchiotti, "Messa in funzione e analisi sperimentale del prototipo di macchina elioassistita" http://www.climatizzazioneconfontirinnovabili.enea.it/index.php/pompe-di-caloreelioassistite/downloads access date 24/05/2021

2. L. A. Tagliafico, F. Scarpa, G. Tagliafico e F. Valsuani, “An approach to energy saving assessment of solar assisted heat pumps for swimming pool water heating" Energy and Buildings, vol. 55, (2012) 
3. L. A. Tagliafico, A. Arteconi, A. Cavalletti, C. Marafioti, A. Marchitto, "Performance Of A Solar Assisted Heat Pump For Building Heating: Control Problems And Improvements", Journal of Physics: Conference Series, vol. 1599, (2020)

4. Terna: Statistical Data on Electricity in Italy-2006 to 2012: Section Power Plants. Available online:

http://www.terna.it/default/home_en/electric_system/statistical_data.aspx (accessed on 17/06/2019)

5. A. Franco, F. Fantozzi, "Optimal sizing of solar assisted heat pump system for residential buildings", Buildings, 10, (2020)

6. R. Wüstenhagen, M. Wolsink e M. J. Bürer, "Social Acceptance of Renewable Energy Innovation: An Introduction to the Concepts" Energy Policy, n. 35, p. 2683 - 2691, (2007)

7. H. C. Kim, "Acceptability engineering: the study of user acceptance of innovative technologies", Journal of Applied Research and Technology, vol. 13, pp. 230-237, (2015)

8. P. D. Wright, "Reconsidering Public Acceptance of Renewable Energy Technologies: a Critical Review" Chapter for inclusion in: Jamasb T., Grubb, M., Pollitt, M. (Eds), Delivering a Low Carbon, (2008)

9. L.A. Tagliafico, A. Cavalletti, C. Marafioti, A. Marchitto "End Users' Acceptance of New Technologies in Building Heating: An Experience on Solar Assisted Heat Pumps", TECNICA ITALIANA-Italian Journal of Engineering Science, vol. 63, pp. 198-204, doi: 10.18280/ti-ijes.632-412. (2019)

10. L.A. Tagliafico, V. Bianco, A. Cavalletti, C. Marafioti, A. Marchitto, F. Scarpa, "Monitoring and control of a pilot plant made of solar assisted heat pump with hybrid panels", AIP Conference Proceedings, Vol. 2191, 020144, doi: 10.1063/1.5138877. (2019) 